\title{
Lymphocyte fluctuation in bronchoalveolar lavage fluid in normal volunteers
}

\author{
MICHEL LAVIOLETTE
}

From the Centre de Pneumologie, Hôpital Laval, Ste-Foy, Quebec, Canada

ABSTRACT In an attempt to understand the widely varying bronchoalveolar lavage lymphocyte counts reported in normal subjects, we performed bronchoalveolar lavage in $\mathbf{4 2}$ healthy nonsmokers. The mean (SD) lymphocyte percentage in this first lavage was $9.6 \%(7.7 \%)$. The values did not fit a normal distribution. Five subjects had more than $20 \%$ of lymphocytes, and when they were excluded the distribution of lymphocyte counts was normal. Bronchoalveolar lavage was repeated once or twice in these five subjects 47 days or more after the previous lavage and the lymphocyte count decreased below $14 \%$ in four. Eight volunteers with an initial lymphocyte percentage less than $20 \%$ also had repeat lavages; two presented a transient increase of lymphocyte count above $20 \%$. These data show that the percentage of lymphocytes in lavage fluid fluctuates significantly in normal subjects and suggest that lymphocyte counts higher than $14 \%$ should not be considered as normal.

Since the fibreoptic bronchoscope has become available, bronchoalveolar lavage has been performed both for research and for the investigation of pulmonary diseases. In clinical practice it is used mostly in the evaluation of interstitial lung diseases. ${ }^{1-4} \mathrm{~A}$ major drawback of this technique is that the differential cell count can vary widely within a normal population. The reported mean values for percentage of lymphocytes in non-smoking controls range from $1 \%$ to $20 \%$. Some authors report low values-namely, 1-7\% 256 - and others intermediate values of $10-15 \%,{ }^{3}$ while others report higher values around $20 \% .^{189}$ In some studies individual lymphocyte counts exceeded $30 \%$ of the cells present. ${ }^{17}$

Many factors may be responsible for the variation in the reported percentage of bronchoalveolar lavage lymphocytes from normal subjects. These include the small number of subjects in some studies, use of control patients instead of healthy volunteers, use of different bronchoalveolar lavage techniques, difficulty in distinguishing large lymphocytes from small macrophages, ${ }^{10}$ and the use of different techniques for determining the differential cell count."

To evaluate bronchoalveolar lavage lymphocyte

Address for reprint requests: Dr Michel Laviolette, Hôpital Laval, 2725 Chemin Ste-Foy, Ste-Foy G1V 4G5, PQ, Canada.

Accepted 29 March 1985 variation in a normal population, we performed lavage in a large number of healthy subjects and did repeated lavage in selected subjects. A transient increase of lymphocyte percentage above $20 \%$ was found in some volunteers who had no clinical evidence of disease. This observation could explain, in part, the wide variation in the lymphocyte percentages previously reported.

\section{Methods}

\section{STUDY POPULATION}

Forty two subjects volunteered for the study. Informed consent was obtained from all subjects. They were 22 men with a mean age of 23.9 years (range 19-32) and 20 women with a mean age of 25.7 years (range 20-41). All were non-smokers; 38 subjects had never smoked while four had stopped smoking at least two years before the study. Twenty nine were students, nine were hospital staff, and four were desk workers. No subject had any pulmonary symptoms or history suggestive of lung disease. Three subjects reported a slight rhinorrhea and one of these had had a dry cough 10-15 days before the study. All were symptomless at the time of bronchoalveolar lavage. Two volunteers had taken acetylsalicylic acid or acetaminophen 21 and 15 days before lavage. All subjects had spirometric tests and measurement of carbon monoxide diffusing capacity (transfer factor). 
LAVAGE PROTOCOL AND PROCESSING OF

LAVAGE FLUID

Bronchoalveolar lavages were done between 8 and 9 am from January 1982 to October 1984. Lavages were performed in the supine position with a fibreoptic bronchoscope of 5.9 or $6.1 \mathrm{~mm}$ external diameter inserted by the mouth after local anaesthesia (Lidocaine 2\% and 4\%, Astra, Ontario). Supplemental oxygen was administered throughout the procedure. With the tip of the bronchoscope gently wedged in a segmental or a subsegmental bronchus of the right middle lobe, aliquots of $0.9 \%$ saline solution at room temperature were instilled and immediately withdrawn by aspiration with a 30 or $20 \mathrm{ml}$ syringe. Suction was applied until the return ceased and the bronchi collapsed. Ten boluses of $30 \mathrm{ml}$ were used in 37 subjects and five boluses of $20 \mathrm{ml}$ in the other five. Lavage fluid was filtered through gauze, collected in $50 \mathrm{ml}$ tubes, and placed on ice until centrifuged $(500 \mathrm{~g}, 10$ minutes at $4^{\circ} \mathrm{C}$ ). The cell pellet was resuspended in Hank's balanced salt solution without $\mathrm{Mg}^{++}$and $\mathrm{Ca}^{++}$or in phosphate buffered saline. The total cell count was made with a haemocytometer. The cell differential count was obtained on both Wright-Giemsa and non-specific esterase stained cytocentrifuged preparations (Cytospin; Shandon, Sewickley, Pennsylvania). Six hundred cells or more (300 in each stain) were counted by the same person. No appreciable blood contamination was found; only a few red cells were sometimes seen.

Lavage was repeated in all five subjects with an initial lavage lymphocyte count higher than $20 \%$ and in eight others who agreed to be restudied. A third lavage was performed in eight subjects who had a lymphocyte percentage higher than $20 \%$ at the second lavage or when lymphocytes had increased between the first and the second bronchoalveolar lavage. At the time of the second and third lavage the subjects had not noted pulmonary or cold symptoms for at least one month before the study. A chest radiograph was obtained in volunteers with a lymphocyte percentage higher than $20 \%$ at the first lavage. The lavage technique described above was used for the second and third lavages. All repeat lavages were performed with a total infused volume of $300 \mathrm{ml}$ in the right middle lobe. In one case, however, the second lavage was performed in the lingula (subject $F$, table 2).

STATISTICAL ANALYSIS OF DATA

Results were analysed by Student's $t$ tests. A $\chi^{2}$ test was used to assess the normality of the distribution of bronchoalveolar lavage lymphocyte percentages. The upper limit of normal for lymphocyte values was determined by the one tailed $95 \%$ confidence interval (mean plus 1.65 standard deviation).

\section{Results}

Lavage was performed without major complications. One volunteer presented with chest pain and dyspnoea a few hours after the procedure and a pneumomediastinum was diagnosed. Her symptoms resolved without treatment within a day. The subjects' physiological and bronchoalveolar lavage characteristics are shown in table 1 . Mean values for all pulmonary function tests were normal. Two subjects had lung volumes below $85 \%$ of predicted normal values and four others had a low diffusing capacity (74-80\% of predicted value). The quantity of fluid recovery ranged from $45.0 \%$ to $82.7 \%$ of the infused volume. Macrophages represented the majority of cells. The mean (SD) percentage of lymphocytes for the group was 9.6 (7.7). Only a few neutrophils were found and in some cases rare eosinophils were also observed.

The figure shows the distribution of lymphocyte percentages. Distribution analysis by $\chi^{2}$ test gave the significant $p$ value of 0.0034 , suggesting that lymphocyte values did not have a normal distribution. The one tailed $95 \%$ confidence interval for lymphocyte percentage was from $9.6 \%$ to $22.3 \%$. Five subjects (two men and three women) had more than $20 \%$ of lymphocytes: $21.4 \%, 22 \%, 23 \%, 26.8 \%$, and $39.8 \%$. All had been free of symptoms for at least a month before the study. Four had normal results in the pulmonary function tests, while in one case lung volumes were $80 \%$ of those predicted. Chest radiographs were obtained initially for four of these subjects. The fifth subject had a chest radiograph done five and a half months later at the time of his second bronchoalveolar lavage, when he had a low lymphocyte count. All radiographs were normal.

Results of repeat lavages for these five subjects and the eight other subjects with less than $20 \%$ of lymphocytes in their initial bronchoalveolar lavage are presented in table 2 . Thirteen volunteers had a second lavage 54-407 days after the first and eight a third lavage 47-413 days after the second. No significant difference was found between first, second, and third lavages for the mean (SD) values of recovered volumes $(71.1(6.1), 72.7(6.2)$, and 70.5 (6.4) respectively); total cell counts (7.1 (3.8), 6.6 (3.0), and $\left.5.8(2.6) \times 10^{4} / \mathrm{ml}\right)$; macrophage percentages (83.1 (10.9), $81.3(7.9)$, and 86.5 (5.2)); lymphocyte percentages $(15.0(11.0), 17.0(8.1)$, and 12.0 (5.7)); and neutrophil percentages (1.8 (1.2), $1.8(1.2)$, and $1.5(1.6))$. Although mean lymphocyte percentages were similar, a large individual fluctuation was present. In four of the five subjects with a percentage of lymphocytes higher than 20 , the lymphocyte percentage fell below 14 (subjects $A, B, C$, and E). One of these five subjects (subject 
Table 1 Results of pulmonary function tests and bronchoalveolar lavage for all subjects (values are means with standard deviations in parentheses and ranges below)

\begin{tabular}{|c|c|c|c|c|c|c|c|c|}
\hline$T L C^{*}$ & $V C^{*}$ & $F E V_{1}^{*}$ & $T L C O^{*}$ & $\begin{array}{l}\text { Fluid } \\
\text { recovered (\% } \\
\text { of infused) }\end{array}$ & $\begin{array}{l}\text { Total No } \\
\text { of cells } \\
\left(\times 10^{4} / \mathrm{ml}\right)\end{array}$ & $\begin{array}{l}\text { Macrophages } \\
\text { (\%) }\end{array}$ & $\begin{array}{l}\text { Lymphocytes } \\
(\%)\end{array}$ & $\begin{array}{l}\text { Neutrophils } \\
\text { (\%) }\end{array}$ \\
\hline $\begin{array}{c}100.3(11.8) \\
80-126\end{array}$ & $\begin{array}{c}101.4(12.3) \\
79-130\end{array}$ & $\begin{array}{c}96.8(11.1) \\
75-116\end{array}$ & $\begin{array}{c}93.3(12.6) \\
74-122\end{array}$ & $\begin{array}{c}69.0(7.3) \\
82.7-45\end{array}$ & $\begin{array}{l}5.8(2.8) \\
1.8-14.4\end{array}$ & $\begin{array}{c}88.6(7.9) \\
60-98.7\end{array}$ & $\begin{array}{l}9.6(7.7) \\
1.0-39.8\end{array}$ & $\begin{array}{c}1.7(1.2) \\
0-4.6\end{array}$ \\
\hline
\end{tabular}

*Expressed as percentages of predicted values.

TLC-total lung capacity; VC-vital capacity; TLCO-transfer factor for carbon monoxide.

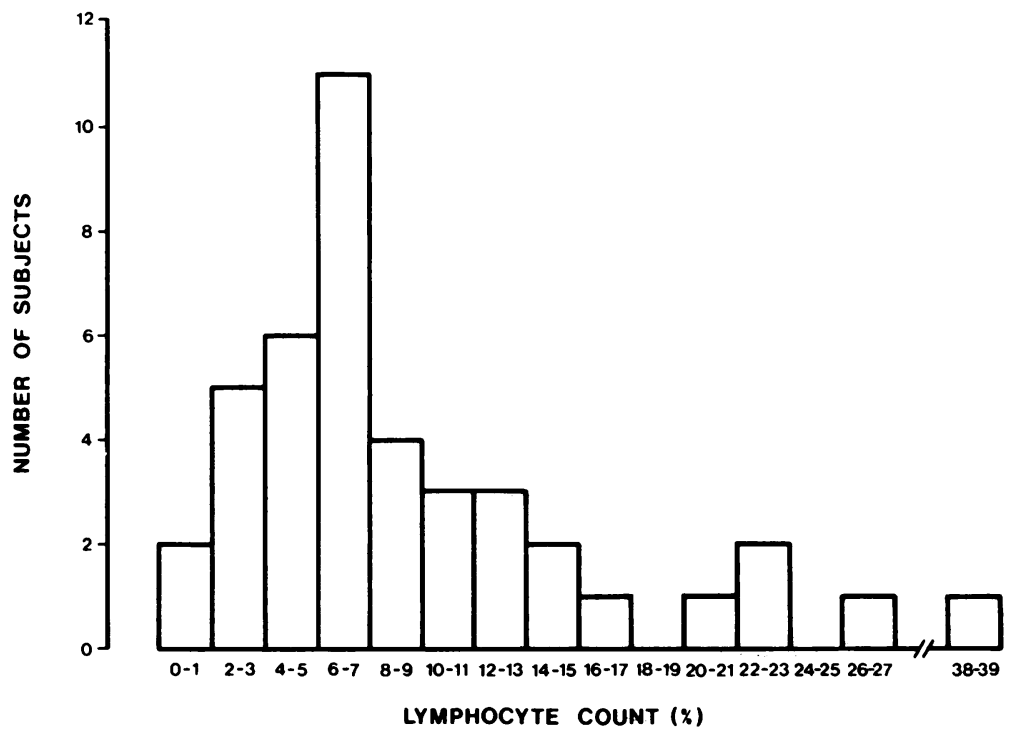

Distribution of bronchoalveolar lavage lymphocyte percentages in 42 healthy non-smoking volunteers. Results do not fit a normal distribution $\left(p=0.0034, \chi^{2}\right.$ test): five subjects had lymphocyte fractions higher than $20 \%$ and those values seem to lie apart from the others. Analysis excluding these five volunteers gives a normal distribution $(p=0.813)$.

D) still had more than $20 \%$ of lymphocytes at the second lavage and refused a third lavage. Her lymphocyte percentage had, however, decreased slightly between the first and second lavage. Of the eight subjects with a lower initial lymphocyte count, two had an increase above $20 \%$ at the second lavage (subjects $\mathrm{F}$ and $\mathrm{I}$ ). In both the percentage fell below 20 at the third lavage. Two other subjects showed a fluctuation of $10 \%$ or more in their lymphocyte count without, however, exceeding $20 \%$ (subjects G and $\mathrm{J}$ ), and the remaining four had smaller variations. Subject $M$ was the only one with a lymphocyte percentage of 15-20 at the first lavage (fig 1). His lymphocyte count increased slightly at the second lavage then decreased to $11 \%$ at the third. The increase in lymphocytes was not related to cold weather; three subjects had a high count in summer, two in autumn, and two in winter. Since the increase in lymphocyte count over $20 \%$ was transient and the five subjects with an initial lymphocyte percentage higher than 20 seemed detached from the others, these five subjects were excluded and a distribution analysis was performed on the 37 remaining first lavage values (figure). Then the distribution of lymphocyte percentages was normal $\left(p=0.813, \chi^{2}\right.$ test $)$; the mean (SD) percentage of lymphocytes was 7.4 (4.0) and the one tailed $95 \%$ confidence interval for lymphocyte percentage was from 7.4 to 14.0 .

\section{Discussion}

This is the first report of sequential lavages in a large number of normal volunteers. The results show that some subjects present a transient increase in bron- 
Table 2 Results of sequential bronchoalveolar lavages (BAL) for the 13 subjects who had repeated lavages

\begin{tabular}{|c|c|c|c|c|c|c|c|}
\hline Subject & $\begin{array}{l}\text { Order } \\
\text { of } B A L\end{array}$ & $\begin{array}{l}\text { Days since } \\
\text { first } B A L\end{array}$ & $\begin{array}{l}\text { Fluid } \\
\text { recovered (\% } \\
\text { of infused) }\end{array}$ & $\begin{array}{l}\text { Total No } \\
\text { of cells } \\
\left(\times 10^{4} / \mathrm{ml}\right)\end{array}$ & $\begin{array}{l}\text { Macrophages } \\
\text { (\%) }\end{array}$ & $\begin{array}{l}\text { Lymphocytes } \\
(\%)\end{array}$ & $\begin{array}{l}\text { Neutrophils } \\
\text { (\%) }\end{array}$ \\
\hline A & $\begin{array}{l}1 \\
2 \\
3\end{array}$ & $\begin{array}{l}161 \\
263\end{array}$ & $\begin{array}{l}66.3 \\
74.3 \\
72.7\end{array}$ & $\begin{array}{l}2.9 \\
5.1 \\
2.3\end{array}$ & $\begin{array}{l}72.3 \\
77.8 \\
90.2\end{array}$ & $\begin{array}{r}26.8 \\
20.5 \\
8.9\end{array}$ & $\begin{array}{l}0.8 \\
1.7 \\
0.9\end{array}$ \\
\hline \multirow[t]{2}{*}{ B } & 1 & & 66.3 & 4.9 & 73.5 & 22.0 & 4.6 \\
\hline & 2 & 271 & 65.7 & 13.8 & 85.7 & 13.0 & 1.0 \\
\hline C & $\begin{array}{l}1 \\
2\end{array}$ & & 82.7 & 4.6 & 76.1 & 21.4 & 2.4 \\
\hline \multirow{2}{*}{ D } & $\begin{array}{l}2 \\
1\end{array}$ & 113 & 68.7 & 5.0 & 87.0 & 9.7 & 3.3 \\
\hline & $\frac{1}{2}$ & 204 & $\begin{array}{l}73.0 \\
78.7\end{array}$ & 2.0 & 74.8 & 23.0 & 2.2 \\
\hline \multirow[t]{2}{*}{$\mathbf{E}$} & 1 & 204 & 78.1 & $\begin{array}{l}2.3 \\
9.0\end{array}$ & $\begin{array}{l}77.5 \\
60.0\end{array}$ & $\begin{array}{l}20.7 \\
39.8\end{array}$ & $\begin{array}{l}1.8 \\
0.2\end{array}$ \\
\hline & $\begin{array}{l}2 \\
3\end{array}$ & 87 & 74.3 & 6.2 & 76.0 & 23.0 & $\begin{array}{l}0.2 \\
1.0\end{array}$ \\
\hline \multirow{3}{*}{$\mathbf{F}$} & $\begin{array}{l}3 \\
1\end{array}$ & 134 & 69.3 & 7.2 & 88.5 & 10.5 & 1.0 \\
\hline & $\frac{1}{2}$ & & 63.0 & 14.4 & 90.0 & 7.3 & 2.8 \\
\hline & 3 & $\begin{array}{r}54 \\
234\end{array}$ & $\begin{array}{l}63.0 \\
717\end{array}$ & 10.4 & 66.0 & 32.1 & 2.7 \\
\hline \multirow[t]{2}{*}{$\mathbf{G}$} & 1 & & 62.0 & $\begin{array}{l}9.9 \\
7.4\end{array}$ & $\begin{array}{l}78.8 \\
93.3\end{array}$ & $\begin{array}{r}19.5 \\
4.3\end{array}$ & $\begin{array}{l}1.7 \\
2.3\end{array}$ \\
\hline & 2 & 118 & 74.7 & 7.3 & 81.7 & 17.5 & 0.7 \\
\hline \multirow{3}{*}{$\mathbf{H}$} & $\begin{array}{l}3 \\
1\end{array}$ & 382 & 61.3 & 4.9 & 83.0 & 16.8 & 0.3 \\
\hline & $\frac{1}{2}$ & 231 & $\begin{array}{l}70.3 \\
73.0\end{array}$ & $\begin{array}{r}10.2 \\
4.8\end{array}$ & $\begin{array}{l}93.0 \\
96.4\end{array}$ & $\begin{array}{l}4.6 \\
27\end{array}$ & 1.6 \\
\hline & 3 & 359 & 71.3 & 4.2 & 89.2 & 5.6 & $\begin{array}{l}0.0 \\
5.4\end{array}$ \\
\hline \multirow[t]{2}{*}{ I } & 1 & & 78.3 & 7.5 & 88.2 & 10.6 & 1.0 \\
\hline & $\begin{array}{l}2 \\
3\end{array}$ & $\begin{array}{l}120 \\
377\end{array}$ & $\begin{array}{l}82.3 \\
80.7\end{array}$ & $\begin{array}{l}5.2 \\
7.3\end{array}$ & $\begin{array}{l}74.5 \\
80.7\end{array}$ & $\begin{array}{l}25.5 \\
18.5\end{array}$ & $\begin{array}{l}0 \\
0.8\end{array}$ \\
\hline \multirow[t]{3}{*}{$\mathbf{J}$} & 1 & & 74.7 & 12.8 & 92.6 & 7.4 & 0 \\
\hline & 2 & 277 & 81.3 & 8.7 & 78.4 & 19.8 & 1.8 \\
\hline & 3 & 690 & 74.7 & 7.5 & 94.0 & 5.0 & 1.0 \\
\hline \multirow[t]{2}{*}{$\mathbf{K}$} & 1 & & 73.0 & 5.6 & 94.2 & 4.5 & 1.2 \\
\hline & 2 & 407 & 77.0 & 4.9 & 91.3 & 7.5 & 1.3 \\
\hline L & $\frac{1}{2}$ & 176 & $\begin{array}{l}75.3 \\
64.3\end{array}$ & $\begin{array}{l}3.5 \\
5.2\end{array}$ & $\begin{array}{l}91.0 \\
86.0\end{array}$ & $\begin{array}{r}7.0 \\
10.1\end{array}$ & $\begin{array}{l}2.0 \\
3.9\end{array}$ \\
\hline \multirow[t]{2}{*}{$\mathbf{M}$} & 1 & & 66.0 & 7.6 & 81.4 & $\begin{array}{l}10.1 \\
16.9\end{array}$ & $\begin{array}{l}3.9 \\
1.7\end{array}$ \\
\hline & $\begin{array}{l}2 \\
3\end{array}$ & $\begin{array}{l}233 \\
544\end{array}$ & $\begin{array}{l}66.0 \\
62.0\end{array}$ & $\begin{array}{l}6.9 \\
3.3\end{array}$ & $\begin{array}{l}78.2 \\
88.0\end{array}$ & $\begin{array}{l}18.9 \\
11.0\end{array}$ & $\begin{array}{l}2.9 \\
1.0\end{array}$ \\
\hline
\end{tabular}

choalveolar lavage lymphocytes without any clinically apparent reason. This individual fluctuation of lymphocyte percentage may explain in part the variation in lavage lymphocyte values previously reported from normal populations.

The infused volume used in this study was larger than in most previously reported ones while other technical aspects were similar. ${ }^{145}$ According to Davies et al,,$^{12}$ the lymphocyte fraction is similar from a small and a large volume lavage and the use of a different volume does not explain lymphocyte variations. The actual counting of cell types could also be a source of variation. Large lymphocytes may sometimes be difficult to distinguish from small macrophages. In an attempt to minimise this problem both Wright-Giemsa and non-specific esterase stained preparations were used and at least 600 cells were counted. The non-specific esterase staining allows for an easier distinction between small macrophages stained in brown and big lymphocytes stained in green. ${ }^{13}$ Recently it has been shown that differential cell counts performed on cytocentrifuged preparations underestimated significantly the bronchoalveolar lavage lymphocyte percentage compared with a cell count performed on filter preparations." This may explain why studies reporting cellular differential counts derived from smears $^{89}$ had a higher percentage of lymphocytes than those using cytocentrifuged preparations. ${ }^{23} 7$ In this study we used cytocentrifuged preparations.

Some reported studies have included either control patients ${ }^{1}$ or a small number of normal volunteers $^{578}$; in this study we included 42 young nonsmokers. Our lymphocyte percentage is situated in the low middle range of the values previously reported, and is similar to the mean value obtained in 44 young non-smokers and reported recently by Reynolds. ${ }^{14}$ We went further than Reynolds by repeating bronchoalveolar lavage in 13 subjects. All five subjects with a lymphocyte count higher than $20 \%$ had repeat lavages. In the distribution curve (figure) they appear detached from the main group and could be considered as having an abnormally high lymphocyte count. The only subject with a mean lymphocyte value in the range 15-20\% (subject $M$, table 2) also agreed to have a repeat lavage. A total of seven subjects had a high lymphocyte count $(>20 \%)$ at the first or second lavage. No sign of pulmonary disease was found to explain these high lavage values. All seven subjects were young, healthy volunteers and were free of any symptom at the time of study. The five subjects with a high lym- 
phocyte count at their first lavage had a normal chest radiograph. Low pulmonary function values (volumes and diffusing capacity) were seen in few subjects, including one of those with a high lymphocyte count at the first lavage. These low values, however, remained within two standard deviations of the distribution of normal subjects as proposed by Berglund et $\mathrm{l}^{15}$ for lung volumes and by Cotes and Hall' for diffusing capacity. These otherwise healthy subjects should therefore be considered as normal and they were not excluded from the study.

An increase in bronchoalveolar lavage lymphocytes has been described in symptomless bird breeders $^{17}$ and farmers. ${ }^{18}$ None of the seven subjects with increased alveolar lymphocytes had had contact with birds or with a farm environment. Recently Wallaert et al reported that a lymphocyte alveolitis (lymphocyte count $>18 \%$ ) could be found in patients with extrathoracic sarcoidosis without clinical, physiological, or radiological evidence pulmonary disease. ${ }^{19}$ No sign of disease developed in our volunteers over the period between lavages when their lymphocyte counts decreased, making subclinical sarcoidosis very unlikely.

In six of the seven subjects with a high lymphocyte count $(>20 \%)$ at the first or second bronchoalveolar lavage, the lymphocyte percentage returned towards lower values at the second or third lavage, below $14 \%$ in four cases and below $20 \%$ in two cases. The lymphocyte alveolitis was therefore a transient phenomenon and may represent a response to an unknown challenge that subsequently disappear. In patients with a previous episode of acute farmer's lung disease, it has been shown that a lymphocyte alveolitis can be found many months after withdrawal from the farm and without clinical signs of disease.$^{20}$ In that disease therefore alveolitis may persist long after the last antigenic contact. In this study, although the subjects denied any respiratory symptom during the month before lavage, it is still possible that a previous cold or some other agent might have provoked an increase of alveolar lymphocytes that could have persisted up to the time of bronchoalveolar lavage. No virological culture or serological studies were performed to investigate this hypothesis.

On the basis of this study $14 \%$ is proposed as the upper limit of normal for the percentage of bronchoalveolar lavage lymphocytes determined from cytocentrifuged preparations. The study shows that some subjects may transiently have higher values without clinically apparent reason. As the high values are transient and fall outside a normal distribution they should be considered abnormal and excluded in the collection of normal values. Such variation decreases the specificity of bronchoalveo- lar lavage and its possible role in the diagnosis of lung diseases. Further studies are needed to define the causes of lymphocyte fluctuation in normal subjects.

This work was supported by grants from the Canadian Lung Association and the Medical Research Council of Canada. I am grateful to Marcelle Carter, Lise Petitclerc, and Aline Huard for technical and fibreoscopy assistance and to Guylaine Labbé for typing the manuscript.

\section{References}

1 Reynolds HY, Fulmer JD, Kazmierowski JA, Roberts WC, Frank MM, Crystal RG. Analysis of cellular and protein content of bronchoalveolar lavage fluid from patients with idiopathic pulmonary fibrosis and chronic hypersensitivity pneumonitis. $J$ Clin Invest 1977;59: 165-75.

2 Weinburger SE, Kelman JA, Elson NA, et al. Bronchoalveolar lavage in interstitial lung disease. Ann Intern Med 1978;89:459-66.

3 Dauber JH, Rossman MD, Daniele RP. Bronchoalveolar cell populations in acute sarcoidosis. Observation in smoking and nonsmoking patients. J Lab Clin Med 1979;94:862-71.

4 Hunninghake GW, Gadek JE, Kawanami O, Ferrans VJ, Crystal RG. Inflammatory and immune processes in the human lung in health and disease: evaluation by bronchoalveolar lavage. Am J Pathol 1979;97:149206.

5 Low RB, Davis GS, Giancola MS. Biochemical analyses of bronchoalveolar lavage fluids of healthy human volunteer smokers and nonsmokers. Am Rev Respir Dis 1978; 118:863-75.

6 Law D, Jackson L, Fulmer J. Bronchoalveolar lavage cellular analysis in the interstitial diseases. A review of 78 cases. Am Rev Respir Dis 1982;125: 105 (abstract).

7 Territo MC, Golde DW. The function of human alveolar macrophages. J Reticuloendothel Soc 1979; 25: 111-20.

8 Warr GA, Martin RR. Immune receptors of human alveolar macrophages: comparison between cigarette smokers and nonsmokers. J Reticuloendothel Soc 1977;22: 181-7.

9 Godard P, Chaintreuil J, Damon M, Coupe M, Flandre $O$, Crastes De Paulet A, Michel FB. Functional assessment of alveolar macrophages: comparison of cells from asthmatic and normal subjects. J Allergy Clin Immunol 1982; 70: 88-93.

10 Fulmer JD. Bronchoalveolar lavage. Am Rev Respir Dis 1982;126:961-3.

11 Saltini C, Hance AJ, Ferrans VJ, Basset F, Bitterman PB, Crystal R. Accurate quantification of cells recovered by bronchoalveolar lavage. Am Rev Respir Dis 1984; 130:650-8.

12 Davis GS, Giancola MS, Costanza MC, Low RB. Analyses of sequential bronchoalveolar lavage samples from healthy human volunteers. Am Rev Respir Dis 1982;126:611-6.

13 Yam LT, Cy LI, Crosby WH. Cytochemical identification of monocytes and granulocytes. Am J Clin Pathol 1971;55:283-90. 
14 Reynolds HY. Lung inflammation: Role of endogenous chemotactic factors in attracting polymorphonuclear granulocytes. Am Rev Respir Dis 1983;127:S1625.

15 Berglund E, Birath G, Bjure J, et al. Spirometric studies in normal subjects. I. Forced expirograms in subjects between 7 and 70 years of age. Acta Med Scand 1963;173:185-91.

16 Cotes JE, Hall AM. The transfer factor for the lung: normal values in adults. In: Arcangdi P, ed. Normal values for respiratory function in man. Torino: Pan Minerva Medica, 1970:327-43.

17 Moore VL, Pedersen GM, Hauser WC, Fink JN. A study of lung lavage materials in patients with hypersensitivity pneumonitis: in vitro response to mitogen and antigen in pigeon breeders' disease. $J$ Allergy Clin
Immunol 1980;65:365-70.

18 Cormier Y, Bélanger J, Beaudoin J, Laviolette $M$, Beaudoin R, Hébert J. Abnormal bronchoalveolar lavage in asymptomatic dairy farmers: study of lymphocytes. Am Rev Respir Dis 1984;130: 1046-9.

19 Wallaert B, Ramon PH, Fournier EC, Prin L, Tonnel AB, Voisin C. Activated alveolar macrophage and lymphocyte alveolitis in extrathoracic sarcoidosis without radiological mediastino-pulmonary involvement. In: Proceedings of 10th International Conference on Sarcoidosis and Other Granulomatous Disorders. (abstract). Ann NY Acad Sci (in press).

20 Leblanc P, Bélanger J, Laviolette M, Cormier Y. Relationship between continued exposure, alveolitis and the clinical state in farmer's lung disease. Chest 1983;84:357 (abstract). 